\title{
PENGARUH KEPEMIMPINAN TRANSFORMASIONAL TERHADAP ORGANIZATIONAL CITIZENSHIP BEHAVIOR (OCB) DENGANKOMPETENSI KOMUNIKASI DAN MOTIVASI SEBAGAI PEMEDIASI
}

\author{
Oleh: \\ Vito Nugraha Soerosemito ${ }^{1)}$, Muhammad Cholil $^{2)}$ \\ ${ }^{1}$ Mahasiswa Magister Manajemen Universitas Sebelas Maret Surakarta \\ ${ }^{2}$ Dosen Fakultas Ekonomi dan Bisnis, Universitas Sebelas Maret Surakarta
}

\begin{abstract}
This study aimed to analyze the influence and leadership relations, communication competence, motivation on organizational citizenship behavior (OCB) employee PDAM Surakarta. The sample in this study amounted to 80 respondents and they are employees of the production, accounting and transmission. Collecting data using direct survey method with questionnaire instrument. Test hypotheses using regression analysis with a significance level of 0.05. Test mediating variables using Baron and Kenny. The results of this research showed that the relationship between transformational leadership and $O C B$ showed that communication competence and motivation mediate its full effect between the leadership of the OCB employee.
\end{abstract}

Keywords: Leadership, Communication, communicative competence, motivation, organizational citizenship behavior, $O C B$

\begin{abstract}
ABSTRAK
Penelitian ini bertujuan untuk menganalisis pengaruh dan hubungan kepemimpinan, kompetensi komunikasi, motivasi pada organizational citizenship behavior (OCB) karyawan PDAM Surakarta. Sampel dalam penelitian ini berjumlah 80 responden dan mereka adalah karyawan bagian produksi, akuntansi dan transmisi. Pengumpulan data menggunakan metode survei langsung dengan instrumen kuisioner. Uji hipotesis menggunakan analisis regresi dengan taraf signifikansi 0,05. Uji variabel mediasi menggunakan metode Baron and Kenny.Hasil dalam penelitian ini menunjukkan bahwa adanya hubungan antara kepemimpinan trasformasional dengan OCB dan menunjukan bahwa komunikasi kompetensi dan motivasi memberikan mediasi penuh terhadap pengaruh antara kepemimpinan dengan $O C B$.
\end{abstract}

Kata Kunci: Kepemimpinan, Komunikasi, kompetensi komunikasi, motivasi,organizational citizenship behavior, $O C B$

\section{A. PENDAHULUAN}

Memasuki era globalisasi, perubahan terjadi begitu cepat. Begitu jugayang terjadi pada dunia usaha, khususnya perusahaan. Perubahan kondisiekonomi, serta perkembangan teknologi menyebabkan banyak perusahaan melakukan langkah restrukturisasi.

Salah satu unsur penting dalam perubahan tersebut ialah peran manusia.Sumber daya manusia 
merupakan aset paling penting dalam suatu organisasi, karena merupakan sumber yang mengendalikan organisasi serta mempertahankan dan mengembangkan organisasi dalam menghadapi berbagai tuntutan zaman. Oleh karena itu sumber daya manusia harus diperhatikan, dijaga dan dikembangkan. Sumber daya manusia perlu dikembangkan secara terus menerus agar diperoleh sumber daya manusia yang bermutu dalam artian sebenarnya yaitu pekerjaan yang dilaksanakan akan menghasilkan sesuatu yang dikehendaki. Oleh karena itu ada deskripsi formal tentang perilaku yang harus dikerjakan (intra-role), dan yang tidak terdeskripsi secara formal yang dilakukan oleh pegawai (extrarole). Hal ini biasa dikenal dengan sebutan Organizational Citizenship Behaviour (OCB).

\section{Organizational}

Citizenship

Behavior (OCB) saat ini menjadi subjek yang sangat menarik dalam literatur manajemen karena dapat mempengaruhi efektifitas dan kinerja organisasi (Robbin \& Judge, 2008). Menurut Podsakof, et al. (2000) tingkat OCB karyawan yang tinggi akan menurunkan tingkat turn over dan ketidakhadiran karyawan. Peranan penting OCB dalam organisasi diperkuat oleh pendapat Robbin dan Judge (2008) yang mengemukakan bahwa organisasi dengan karyawan yang memiliki tingkat OCB tinggi akan memiliki kinerja yang lebih efektif dari organisasi lain.

Dalam dunia kerja yang dinamis seperti saat ini, dimana tugas semakin sering dikerjakan dalam tim dan fleksibilitas sangatlah penting, organisasi membutuhkan anggota yang memperlihatkan perilaku OCB. Perilaku OCB yang dimaksud seperti membantu individu lain dalam tim, mengajukan diri untuk melakukan pekerjaan ekstra, menghindari konflik yang tidak perlu, menghormati semangat dan isi peraturan, serta dengan besar hati mentoleransi kerugian dan gangguan terkait pekerjaan yang kadang terjadi (Robbins, 2008).

OCB berkontribusi kepada pemeliharaan dan peningkatan konteks sosial dan psikologis dalam tugas dukungan kinerja. Menurut Nielsen (2012), OCB melibatkan beberapa perilaku meliputi perilaku suka menolong orang lain, menjadi volunteer untuk tugas-tugas ekstra, dan patuh terhadap aturan-aturan dan prosedurprosedur di tempat kerja. 


\begin{abstract}
Robbins (2008) menyatakan
bahwa kepemimpinan merupakan kemampuan untuk mempengaruhi suatu kelompok ke arah tercapainya suatu tujuan. Bass (1999) membagi kepemimpinan dalam dua gaya yaitu gaya kepemimpinan transformasional dan gaya kepemimpinan transaksional. Gaya kepemimpinan transformasional adalah sutau gaya kepemimpinan yang memperlakukan bawahan sebagai partner kerja dan menganggap mereka sudah dewasa dalam melaksanakan pekerjaan atau perintah. Sedangkan kepemimpinan transaksional adalah gaya kepemimpinan yang memperlakukan bawahan untuk mendapat sanksi/hukuman atau hadiah dalam pelaksanaan tugas/perintah.
\end{abstract}

Kepemimpinan merupakan kunci utama dalam manajemen yang memainkan peran penting dan strategis dalam kelangsungan hidup suatu perusahaan. Pemimpin merupakan pencetus tujuan, merencanakan, mengorganisasikan, menggerakkan dan mengendalikan seluruh sumber daya yang dimiliki sehingga tujuan perusahaan dapat tercapai secara efektif dan efisien. Oleh sebab itu pemimpin suatu organisasi/perusahaan dituntut untuk selalu mampu menciptakan kondisi yang memuaskan karyawan dalam bekerja sehingga diperoleh karyawan yang tidak hanya mampu bekerja akan tetapi juga bersedia bekerja ke arah pencapaian tujuan perusahaan.

Menurut Duncan dan Moriarty (1998), komunikasi adalah aktivitas manusia yang menghubungkan orang bersama-sama dan menciptakan hubungan. Dengan kata lain, setiap individu berhubungan dengan individu lain dengan cara komunikasi (Sanford, Hunt, \& Bracey, 1976). Cooren (1999) dan Schwartzman mengemukakan bahwa komunikasi merupakan tindakan dari suatu organisasi dan karya-karya pengorganisasian, koordinasi, menginformasikan, mengatur, mensubordinasi dan sebagainya dilakukan oleh tindakan komunikatif. komunikasi yang signifikan lebih dari sekedar pemberian informasi (Zhu, Mei, \& Rosenfeld, 2004). Bahkan komunikasi memiliki peran penting dalam kegagalan, atau prestasi dari setiap organisasi (Orpen, 1997).

Berdasarkan penjelasan di atas, secara umum dapat diketahui bahwa kepemimpinan berpengaruh pada kompetensi komunikasi dan motivasi, 
dan kompetensi komunikasi dan motivasi berpengaruh pada OCB.

Hal ini didukung oleh penelitian beberapa hasil penelitian sebelumnya.Shani dan Somech (2011)melakukan penelitian tentang kepemimpinan transformasional dan OCB.Hasil penelitian menyatakan bahwa transformasional dan transaksional perilaku pemimpin masing-masing positif atau negatif terkait dengan $\mathrm{OCB}$, tergantung pada tingkat pengikut 'dari idiocentrism dan allocentrism.Dalam penelitian Osman YILDIRIM (2014) melakukan penelitian tentang kompetensi komunikasi dan OCB, Hasil penelitian menyatakanbahwa ada korelasi antara komunikasi organisasi dan organization citizenship behavior karyawan.George dan Jones (2005) melakukan penelitian tentang Motivasi dan OCB. Hasil penelitian menyatakan bahwa motivasi kerja yang tinggi sangat mempengaruhi timbulnya perilaku OCB di perusahaan. Menurut Abubakar (2010) melakukan penelitian tentang kepemimpinan dan kompetensi komunikasi. Hasil penelitian menyatakan bahwa kepemimpin dapat berhubungan dengan komunikasi. Menurut Olyvia Yancomala (2014) bahwa terdapat hubungan yang berarti antara gaya kepemimpinan dengan motivasi

\section{B. METODE PENELITIAN}

Penelitian ini menggunakan desain penelitian deskriptif dengan pendekatan kuantitatif. Penelitian ini dilaksanakan di $\quad$ PDAM Surakarta.Variabel yang digunakan dalam penelitian ini adalah gaya kepemimpinan transformasional (X), kompetensi komunikasi (M1), motivasi (M2) dan organizational citizenship behavior (Y).

Berdasarkan kajian teori dan penelitian terdahulu, hipotesis yang diajukan dalam penelitian ini adalah:

1. H1 : Kepemimpinan memiliki pengaruh positif terhadap OCB

2. H2 : Komunikasi memiliki pengaruh positif terhadap OCB

3. H3 : Motivasi memiliki pengaruh positif terhadap OCB

4. H4 : Kepemimpinan memiliki pengaruh positif terhadap kompetensi komunikasi

5. H5: Kepemimpinan memiliki pengaruh positif terhadap motivasi

6. H6:Kompetensi Komunikasi memediasi pengaruh antara kepemimpinan terhadap OCB 
7. H7: Motivasi memediasi pengaruh antara kepemimpinan terhadap OCB

Populasi dalam penelitian ini adalah seluruh karyawan PDAM Surakarta dari semua divisi perusahaan. Populasi ini berjumlah 400 karyawan antara lain menempati bagian produksi, transmisi, dan keuangan.

$$
\text { Sampel penelitian dalam }
$$
penelitian ini adalah karyawan PDAM Surakarta dengan jumlah 80 orang. Instrumen penelitian untuk pengumpulan data dalam penelitian ini menggunakan kuesioner. Teknik analisis data menggunakan analisis regresi dengan taraf signifikansi 0.05 . Uji pengaruh mediasi dalam penelitian ini menggunakan metode Barond and Keny

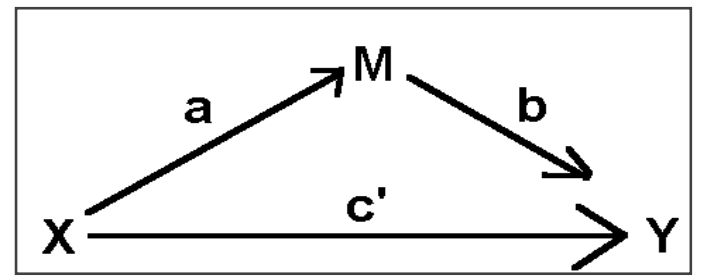

Sumber: David A. Kenny, 2015 Gambar 2 Model Mediasi Baron and Kenny

Keterangan:

Variabel bebas $=\mathrm{X}$

Variabel Mediasi $=\mathrm{M}$

Variabel terikat $=\mathrm{Y}$

Metode ini menunjukkan
serangkaian langkah yang harus dipenuhi untuk model mediasi yaitu: (1) Regresikan X ke Y yang disimbolkan dengan jalur c, (2) Regresikan X ke M yang disimbolkan dengan jalur a, (3) Regresikan M ke Y yang disimbolkan dengan jalur b, (4) Regresikan X dan M ke $\mathrm{Y}$, sehingga akan diperoleh korelasi M ke Y (jalur b),dan X ke Y (jalur c'). Baron and Kenny menyatakan bahwa suatu variabel dapat dikatakan berfungsi sebagai variabel pemediasi apabila memenuhi kondisi-kondisi seperti dijelaskan berikut ini:

1. Pengaruh mediasi penuh akan terjadi apabila variabel gaya kepemimpinan yang semula berpengaruh signifikan menjadi tidak berpengaruh signifikan pada OCB saat variabel kepuasan kerja dikontrol

2. Apabila signifikansi variabel gaya kepemimpinan meningkat atau menurun pada variabel OCB dikontrol, maka yang terjadi adalah mediasi parsial. 
C. HASIL DAN PEMBAHASAN

Tabel 1.Hasil Uji regresi

\begin{tabular}{cccc}
$\begin{array}{c}\text { Variab } \\
\text { el }\end{array}$ & $\begin{array}{c}\text { Bet } \\
\text { a }\end{array}$ & $\begin{array}{c}\text { Signifika } \\
\text { nsi }\end{array}$ & $\begin{array}{c}\text { Keterang } \\
\text { an }\end{array}$ \\
\hline $\mathrm{X} 1 \rightarrow \mathrm{Y}$ & 0,28 & 0,000 & $\begin{array}{c}\text { Hipotesis } \\
1 \text { diterima }\end{array}$ \\
$\mathrm{M} 1 \rightarrow$ & 0,50 & 0,000 & $\begin{array}{c}\text { Hipotesis } \\
\text { 2 diterima }\end{array}$ \\
$\mathrm{Y}$ & 2 & & Hipotesis \\
$\mathrm{M} 2 \rightarrow$ & 0,37 & 0,002 & 3 diterima \\
$\mathrm{Y}$ & 7 & & Hipotesis \\
$\mathrm{X} \rightarrow \mathrm{M}$ & 0,38 & 0,000 & 4 diterima \\
1 & 4 & & Hipotesis \\
$\mathrm{X} \rightarrow$ & 0,48 & 0,000 & 5 diterima \\
$\mathrm{M} 2$ & 8 & & Hipotesis \\
$\mathrm{X} \rightarrow$ & 0,10 & 0,388 & 6 diterima \\
$\mathrm{M} 1$ & 1 & & Hipotesis \\
$\rightarrow \mathrm{Y}$ & & & 7 diterima \\
$\mathrm{X} \rightarrow$ & 0,09 & 0,374 & \\
$\mathrm{M} 2 \rightarrow$ & 1 & & \\
$\mathrm{Y}$ & & &
\end{tabular}

Sumber: data primer diolah

Keterangan :

$\mathrm{X}$ :kepemimpinan transformasional

M1: kompetensi komunikasi

M2: Motivasi

Y: OCB

Dalam analisis regresi, uji hipotesis diterima nilai signifikansi kurang dari taraf signifikansi yang ditetapkan (Imam Ghozali,2013). Dalam penelitian ini taraf signifikansi yang ditetapkan adalah 0.05 . Berdasarkan tabel diatas, dapat diketahui bahwa semua hipotesis yang diajukan dalam penelitian ini diterima.

\section{SIMPULAN}

Simpulan penelitian dimaksudkan untuk memperrmudah memahami hasil penelitian yang telah dilakukn. Simpulan yang dapat diperoleh dari penelitian ini adalah:

1. Kepemimpinan berpengaruh signifikan untuk meningkatkan Organizational Citizenship Behavior karyawan Perusahaan Daerah Air Minum Kota Surakarta, berdasarkan nilai probabilitas < 0,05. Maka hipotesis pertama terbukti (didukung) dalam penelitian ini.

2. Kompetenssi Komunikasi dari atasan berpengaruh signifikan untuk meningkatkan Organizational Citizenship Behavior karyawan Perusahaan Daerah Air Minum Kota Surakarta, berdasarkan nilai probabilitas $<0,05$. Maka hipotesis kedua terbukti (didukung) dalam penelitian ini.

3. Motivasi dari pimpinan berpengaruh signifikan meningkatkan Organizational Citizenship Behavior pada karyawan Perusahaan Daerah Air Minum Kota Surakarta, berdasarkan nilai probabilitas $<0,05$. Maka hipotesis ketiga dalam penelitian ini terbukti.

4. Kepemimpinan berpengaruh signifikan meningkatkan kompetensi komunikasi pada pimpinan 
Perusahaan Daerah Air Minum Kota

Surakarta, berdasarkan nilai probabilitas $<0,05$. Maka hipotesis keempat dalam penelitian ini terbukti.

5. Kepemimpinan atasan berpengaruh signifikan meningkatkan motivasi kerja pada karyawan Perusahaan Daerah Air Minum Kota Surakarta, berdasarkan nilai probabilitas < 0,05. Maka hipotesis kelima dalam penelitian ini terbukti.

6. Kompetnsi komunikasi memediasi secara penuh pengaruh kepemimpinan terhadap Organizational Citizenship
Behavior pada karyawan Perusahaan Daerah Air Minum Kota Surakarta, berdasarkan hasil persamaan jalur $a$ diperoleh $\mathrm{p}<0,05$ dan jalur $b$ dengan $\mathrm{p}<0,05$ dan pada jalur c' $\mathrm{p}>0,05$.

7. Motivasi pimpinan memediasi secara penuh pengaruh kepemimpinan terhadap Organizational Citizenship Behavior pada karyawan Perusahaan Daerah Air Minum Kota Surakarta, berdasarkan hasil persamaan jalur $a$ diperoleh $\mathrm{p}<0,05$ dan jalur $b$ dengan $\mathrm{p}<0,05$ dan pada jalur $c^{\prime} \mathrm{p}>0,05$.

\section{DAFTAR PUSTAKA}

Akmal I. M.,\& Aslinda (2014). The effect of motivation on organizational citizenship behavior (OCB) at telkom indonesia in makassar. International Journal of Administrative Science \& Organization 2014. Vol.21. no.2

Baron, R. M., \& Kenny, D. A. (1986). The moderator-mediator variabledistinction in social psychological research: Conceptual, strategic and statistical considerations. Journal of Personality and Social Psychology, 51, No. 6, pp 173182

Erick A.N., dan Eddy M. S. (2014). Pengaruh motivasi dan kepuasan kerja karyawan terhadap organizational citizenship behavior. Jurnal Manajemen, Vol. 2, Nomor 1,2014

Flauto, Frank, J. (1999). Walking The Talk: The Relationship Between Leadership and Communication Competence, The Journal of Leadership Studies, 6(1/2), 86-97. 
Ghozali, I. (2013). Aplikasi Analisis Multivariate Dengan Program, Edisi Ketujuh. Semarang: Badan Penerbit Universitas Diponegoro

Herfina., Abdullah, T.,\& Rubini, B. (2015). The Relationship among Transformational Leadership, Work Satisfaction, and Interpersonal Communication to Teachers' Organizational Citizenship Behavior, International Journal of Managerial Studies and Research (IJMSR) Volume 3, Issue 4, April 2015, PP 11-16

Hilmi. (2011). Kepemimpinan Transformasional dan Perilaku Kewargaan Organisasional di Politeknik Negeri Lhoksumawe,. - J urnal Perspektif Manajemen dan Perbankan 2, No.1, 2011, pp. 192-198.

J. Kevin Barge., \&RANDY Y. HIROKAWA (1989), Toward a communication competency model of group leadership. Small Group Behavior. Vol 20 No 2, May 19R9 167-189

Jubaedah, Edah (2009).Analisis hubungan gaya kepemimpinan dan kompetensi komunikasi dalam organisasi. Jurnal Ilmu Administrasi Volume VI No. 4 Desember 2009

Madlock, Paul, E. (2008). The Link Between Leadership Style, Communicator Competence, and Employee Satisfaction, Journal of Business Communication, $45(1), 61-78$

Saeed H. Maryam., \& Irshad R., (2014). How transformational leadership is related to organizational citizenship behavior? The mediating role of emotional intelligence. Pakistan Journal of Commerce and Social Sciences 2014, Vol. 8 (2), $413-425$

Simcic B. P. (2013). How others see us: leaders' perceptions of communication and communication managers. Journal of Communication Management. Vol. 18 No. 1, 2014. pp. 58-79

Susanty Aries, \& Wahyu B. S., (2012). Pengaruh motivasi kerja dan gaya kepemimpinan terhadap disiplin kerja serta dampaknya pada kinerja karyawan (studi kasus pada pt. Pln (persero) apd semarang). J@TI Undip, Vol VII, No 2, Mei 2012

YILDIRIM Osman (2014). The impact of organizational communication onOrganizational citizenship behavior: research findings. Social and Behavioral Sciences 150 ( 2014 ).pp.1095 - 1100

Zabihi, M., \& Hashemzehi, R. (2012). The relationship between leadership styles and organizational citizenship behavior. African Journal of Business Management. 
Vito, Pengaruh Kepemimpinan Transformasional Terhadap Organizational

Vol. 6 (9), pp. 3310-3319

Zulbadi., Umi A. H., \& Dahniar (2014). Pengaruh Kepemimpinantransformasional dan komitmen organisasi terhadap organizational citizenship behavior (ocb) terhadap karyawan pdam bandarmasih kota banjarmasin. Jurnal Wawasan Manajemen, Vol. 2, Nomor 1, Februari 2014 